\title{
Avaliação da Hanseníase: relato de experiência de acadêmicos de enfermagem
}

Leprosy assessment: experience report of nursing students

Evaluación de la Lepra: relato de experiencia de estudiantes de enfermería

\author{
Sandra Valéria Martins Pereira', Maria Márcia Bachion", \\ Aliny Gracielly Crispim de Souza"II, Sâmia Maria Skaff Vieira' \\ 'Centro Universitário de Anápolis. Curso de Enfermagem. Anápolis, GO \\ "Universidade Federal de Goiás. Departamento de Enfermagem. Goiânia, GO \\ II'Hospital de Doenças Tropicais. Goiânia, GO
}

Submissão: 29/08/2008

Aprovação: 24/10/2008

\begin{abstract}
RESUMO
O Brasil é o segundo no mundo em novos casos de hanseníase. O controle da doença continua sendo uma meta desafiante. Buscou-se descrever o perfil morfológico de lesões cutâneas e outras seqüelas e analisar a conduta adotada no cuidado de feridas de um grupo de pessoas com seQüelas de hanseníase asiladas em uma instituição não governamental. A experiência de ensino-aprendizagem foi longitudinal, fundamentada na Metodologia Científica da Assistência de Enfermagem, envolvendo pessoas com seeüelas de Hanseníase asilados em uma instituição não governamental do estado de Goiás. O perfil morfológico das lesões foi: déficit visual, madarose, desabamento da pirâmide nasal, reabsorção de dedos e artelhos, amputação de membros, mal perfurante plantar e garra ulnar. Detectou-se prejuízo da cicatrização devido à aplicação direta e rotineira de sabões abrasivos e anti-sépticos nas lesões.
\end{abstract}

Descritores: Hanseníase/Complicações; Enfermagem; Assistência de enfermagem.

ABSTRACT

Brazil is the second in the world in new cases of Leprosy. The eradication continues to be a defiant goal. It has sought describe the morphologic profile of lesion formations and analyze the procedures in the care of wounds from a group of people with seQuelae of Hansen asylum in an institution non-governmental. The experience of teaching-learning was longitudinal, based on Scientific Methodology of Nursing Assistance, involving people with swellings and health repercussions of Hansen's disease, residents in an institution of Goiás State. All the residents presented disabling swellings and health repercussions associated to the Leprosy: visual impediment, swelling of the eyebrows; fall of the nasal pyramid, total reabsorption of fingers and toes, amputation of both legs, ulna grip, perforating plantar disease. Abrasive soaps and toxic antiseptic were applied directly on the lesion, causing damages to the scarring.

Descriptors: Leprosy/Complications, Nursing; Nursing care.

\section{RESUMEN}

Brasil es el segundo país en el mundo en nuevos casos de Enfermedad de Hansen (Lepra). La eliminación continúa siendo una meta desafiadora. Buscamos describir el perfil morfológico de lesiones cutáneas y secuelas y analizar la conducta adoptada para cuidado de las heridas de un grupo de personas con secuelas de Enfermedad de Hansen de un asilo no gubernamental. La experiencia de enseñanzaaprendizaje se longitudinal, fundamentado en la Metodología Científica de la Asistencia de Enfermería, incluyendo personas con lesiones y secuelas de lepra, internadas en una institución del Estado de Goiás. Todos los internos presentaban lesiones y secuelas de incapacidad asociadas a la lepra: déficit visual, madarosis; caída de la pirámide nasal, reabsorción total de dedos y dedos de los pies, amputación de ambas piernas, mal perforante plantar y garra ulnar. Jabones abrasivos y antisépticos tóxicos eran aplicados directamente en las lesiones, causando prejuicios a la cicatrización.

Descriptores: Lepra/Complicaciones; Enfermería; Atención de enfermería.

Correspondência: Sandra Valéria Martins Pereira. UNIEvangélica. Curso de Enfermagem. Av. Universitária Km. 3,5 - Cidade Universitária. CEP 75083-515. Anápolis, GO. 


\section{INTRODUÇÃO}

A hanseníase é uma doença infecto-contagiosa causada pelo Micobacterium leprae, um bacilo intracelular obrigatório com afinidade pelas células da pele e dos nervos periféricos. A principal característica clínica é o acometimento dermato-neurológico, Que pode levar as deformidades ósteo-articulares e outras seQüelas. Tais eventos expressam a má condução e falta de controle do caso, tais como: diagnóstico tardio, tratamento inadequado ou abandono da polieuimioterapia.

As seQüelas podem ser desfigurantes, mutilantes e incapacitantes, Que na maioria das vezes desencadeia transtornos de ordem multidimensional, inclusive aqueles decorrentes do estigma, abandono familiar e exclusão social.

O diagnóstico e tratamento da hanseníase são ambulatoriais, sendo Que os esquemas de polieuimioterapia (PQT), recomendados pela Organização Mundial de Saúde (OMS), se cumpridos rigorosamente levam à cura em períodos relativamente $\operatorname{curtos}^{(1)}$. A PQT é constituída pela associação de dapsona, clofazimina e rifampicina.

Atualmente, observa-se Que nem mesmo os avanços relativos à facilidade de acesso ao tratamento ambulatorial oferecidos pelo Sistema Único de Saúde (SUS), conseguiram mudar a situação desvantajosa do País, Que continua ocupando o segundo lugar no hanking mundial, em novos casos de hanseníase ${ }^{(2)}$.

A partir de 2008, o Pacto pela Saúde adotou o coeficiente de detecção da hanseníase como indicador primário da efetividade e resultado do tratamento. O principal indicador epidemiológico é o coeficiente de detecção em menores de 15 anos, Que expressa a força de transmissão recente e suas tendências ${ }^{(3)}$.

Em 2005, o coeficiente de detecção de casos novos de hanseníase no País foi 2,08/10 000 hab (34.41 8), com significado endêmico muito alto. Na região Centro Oeste e no estado de Goiás, coeficiente de detecção foi de 4,4l e 4,02/10.000 hab, caracterizando respectivamente, áreas hiperendêmica e de deteç̧ão muito alta. No município da pesQuisa, em 2005, havia 266 pacientes em registro ativo, mas apenas 165 em tratamento. O coeficiente de detecção foi de $1,82 / 10.000$ hab $^{(2)}$.

Nesse contexto, o plano estratégico do Ministério da Saúde, segue as diretrizes da OMS, Que consiste em intensificar as ações de vigilância resolutiva e contínua, principalmente nas áreas selecionadas como prioritárias pelo Programa Nacional de Controle da Hanseníase (PNCH). A meta é alcançar baixos níveis endêmicos, assegurando Que as atividades de controle da hanseníase estejam descentralizadas, disponíveis e acessíveis a todos os indivíduos nos serviços de saúde mais próximos de suas residências ${ }^{(3)}$.

No estado de Goiás vários municípios são classificados como endêmicos, sendo Que o grande desafio consiste em reduzir, em 2008, a prevalência e a detecção de casos novos de hanseníase para menos de um caso por cada 10.000 habitantes.

Em 2010, a meta de prevalência é de menos de um caso por cada 10.000 habitantes em todos os municípios do País.

O período de incubação da hanseníase varia de dois a sete anos, sendo de evolução insidiosa e de grande potencial incapacitante, o Que torna o diagnóstico precoce seu objetivo primeiro. A hanseníase é classificada segundo o aspecto, Quantidade e gravidade das lesões em: indeterminada, tuberculóide, dimorfa e virchoviana ${ }^{(4)}$.
A mudança do Quadro epidemiológico no País é uma Questão multidimensional, onde as ações cuidativas de enfermagem por serem individualizadas e contínuas são fundamentais no âmbito da ęuipe muldisciplinar.

A capacidade de julgamento clínico e a tomada de decisão do enfermeiro dependem do seu conhecimento científico, experiência e aprimoramento constante. Nesse sentido, a melhor forma da academia de enfermagem instrumentalizar futuros profissionais para atuar nessa realidade, é lhes propiciando situações de embate com a realidade, onde possam apreender conceitos, reconhecer formas clínicas, discutirem soluções em busca da transformação da realidade.

Nessa perspectiva, elegemos como proposta de atividade pedagógica para o estágio supervisionado em ações básicas de saúde, a intervenção de enfermagem voltada para um grupo de pessoas em condição social desprivilegiada, Que além das seQüelas de hanseníase optaram pelo confinamento, justamente pela condição de excluídos do âmago familiar, sendo Que não conseguiram se reintegrar á sociedade, conforme apontam as diretrizes das políticas públicas do setor saúde.

A partir da riqueza das vivências no estágio supervisionado, entendemos Que a descrição da experiência pode corroborar para reflexão e planejamento estratégico de saúde, bem como estimular ações pedagógicas problematizadoras e inovadoras nesse sentido.

Este estudo teve como objetivos:

- Descrever o perfil morfológico de lesões cutâneas e outras seQüelas encontradas em pessoas assistidas durante um Estágio Supervisionado de Enfermagem;

- Analisar a conduta adotada de autocuidado das feridas em um grupo de pessoas com seeüelas de hanseníase asiladas em uma instituição não governamental do estado de Goiás.

\section{TRAJETÓRIA, ESTRUTURA E ESTRATÉGIAS DA EXPERIÊNCIA PEDAGÓGICA}

A experiência envolveu 12 participantes, abordados no período de junho a Dezembro de 2007, por ocasião do estágio curricular supervisionado de enfermagem em ações básicas de saúde.

O cenário da experiência foi uma instituição de saúde não governamental, sediada no estado de Goiás, mantida por doações e mão de obra de saúde de caráter voluntário.

A missão da referida instituição consiste em amparar o portador de hanseníase ou de suas seQüelas, em condição de abandono. Tratase de uma ampla casa, com dormitórios e áreas adaptadas para o cuidado e autocuidado de saúde, refeitório coletivo e quintal sem benfeitorias. E apesar do ambiente bastante doméstico, atende as exigências da Vigilância Sanitária.

A maioria dos internos não apresentava indicações clínicas para internação hospitalar, pois eram parcialmente dependentes, e mesmo de forma precária ou inadeQuada praticavam o autocuidado de higiene, alimentação e com as feridas. Dessa forma, não os consideramos como pacientes, visto Que eram adeptos ao confinamento espontâneo, por falta de teto e de família.

A estratégia pedagógica eleita para o estágio supervisionado foi a Metodologia Científica da Assistência de Enfermagem ou Processo de Enfermagem, Que constituiu o eixo norteador para o processo de cuidar. Este método é utilizado na prática clínica e pedagógica com êxito. Suas etapas sistematizadas são correlatas às do método 
científico, sendo operacionalizado com êxito na pesquisa clínica de enfermagem em diversas especialidades ${ }^{(5,6)}$.

O enfoque das atividades práticas foi o desenvolvimento de habilidades e competências dos acadêmicos para consulta de enfermagem de enfermagem focalizada no portador de hanseníase ou secüelas, e mais especificamente para operacionalização da primeira fase da metodologia da assistência denominada assessment, Que constitui uma ampla e criteriosa avaliação de enfermagem voltada para mensuração de indicadores relativos ao estado de saúde do cliente, sendo que o julgamento dos dados clínicos juntamente com outros aspectos sócio-culturais e demográficos subsidia a tomada decisão do enfermeiro em relação ao planejamento, prescrição, implementação e avaliação dos resultados do cliente frente à intervenção de enfermagem ${ }^{(6)}$.

As bases clínicas do assessment foram: a classificação do tipo de hanseníase, a definição dos indicadores de integridade da pele e tecidos, a mobilidade física e o grau de incapacidade, selecionados com base nas normas técnicas para tratamento de hanseníase do Ministério da saúde e outras literaturas científicas na área ${ }^{(4,7,8)}$ :

Para julgamento clínico consideramos as peculiaridades clínicas dos tipos de hanseníase ${ }^{(4)}$ :

- hanseníase indeterminada (HD), de baciloscopia negativa, paucibacilar (presença de $<5$ lesões), caracterizada por manchas hipocrômicas, únicas ou múltiplas, alterações superficiais da sensibilidade (hipoestesia, hiperestesia), anestesia térmica, com preservação dolorosa e tátil, sem lesão cutânea, sem expressão clínica de comprometimento de troncos nervosos;

- hanseníase tuberculoide (HT), baciloscopia negativa, paucibacilar, caracterizada por lesões eritemato-hipocrômicas, eritematosas, eritemato-escamosas, com bordas discretamente elevadas, microtubérculos, de centro aparentemente poupado, comprometimento assimétrico de nervos e da sensibilidade superficial (hipoestesia, anestesia térmica, dolorosa e tátil), calosidades e úlceras profundas localizadas em áreas de compressão óssea, alopécia e anidrose;

- hanseníase dimorfa (HD), baciloscopia positiva ou negativa, multicibacilar, caracterizada por lesões eritematosas, eritemovioláceas, ferruginosas, infiltradas, edematosas, brilhantes, escamosas com contornos internos bem definidos e externos mal definidos, centro deprimido, hipocrômico ou de coloração normal, com hipoestesia ou anestesia, comprometimento neurológico troncular e episódios reacionais de elevado potencial incapacitante, Que clinicamente podem se aproximar do pólo virchowiano ou tuberculóide, no primeiro prevalece nódulos, infiltrações na face e pavilhões auriculares e no segundo lesões cutâneas menos numerosas e assimétricas;

- hanseníase virchowiana (HV), baciloscopia positiva, multicibacilar, caracterizada por infiltração difusa com numerosas lesões eritematosas, eritemato-acastanhadas, infiltradas, brilhantes, coalescentes, mal definidas, de distribuição simétrica, tubérculos e nódulos, perda definitiva de pêlos dos cílios e supercílios (madarose), fácies leonina, distúrbios sensitivos cutâneos, comprometimento dos troncos nervosos e de vísceras.

Consideramos ainda, a classificação das lesões neurogênicas em primárias e secundárias. As primárias decorrentes da resposta tecidual à presença do bacilo nos tecidos, como déficits sensitivos, motores e autonômicos e as secundárias caracterizadas pelo comprometimento da pele e anexos, cartilagens, ossos, articulações (retrações, contraturas, lesões traumáticas e infecções póstraumáticas), lesões do globo ocular e das vísceras ${ }^{(4)}$ :

- comprometimento dos olhos, caracterizado por ressecamento, alteração da sensibilidade e da força muscular das pálpebras, Que podem provocar fenda palpebral e inversão dos cílios (triQuíase);

- comprometimento da mucosa nasal, caracterizado por hansenomas, infiltrações, obstrução, aumento da secreção nasal e da viscosidade, com formação de crostas de odor fétido, desabamento da pirâmide nasal, com perfuração da cartilagem septal;

- megalóbulo ou orelha em "figo seco", inflamação da cartilagem da orelha e aumento da orelha por proliferação de estruturas da cartilagem;

- madarose superciliar e ciliar, Queda dos pelos da sombrancelha e dos cílios;

- incapacidade e deformidade das mãos dos pés, tais como: ressecamento, perda de sensibilidade protetora, fraeueza muscular, fissuras, encurtamento ou retração de tecidos moles, úlceras, garra ulnar e garra de artelhos;

O grau de incapacidade dos participantes foi classificado de acordo com a Norma Técnica do Ministério da Saúde ${ }^{(3)}$ :

- grau 0, Quando não há comprometimento neural nos olhos, mãos ou pés;

- grau I, Que corresponde a diminuição ou a perda da sensibilidade nos olhos, nas mãos e nos pés;

- grau II, Que indica a presença de incapacidades e deformidades dos olhos (lagoftalmo e/ou ectrópio, trieuíase, opacidade corneana, acuidade visual $<0,1$ ), das mãos e dos pés (lesões tróficas, garras, reabsorção óssea, mãos e/ou pés caídos, mutilações e contraturas dos tornozelos).

Foi desenvolvido um instrumento de coleta de dados, com enfoque na descrição do perfil de seqüelas: lesões cutâneas e comprometimento neurogênico dos participantes, Que consistiu um roteiro para exame físico, com a finalidade de estabelecer um padrão de interpretação dos indicadores, melhorando o padrão do julgamento clínico e dos registros de enfermagem. Ao término do estágio, os acadêmicos apresentaram um estudo de caso clínico com enfoque holístico.

Os participantes foram abordados antes e durante o cuidado, dentro dos princípios de ética, preservando-lhes a individualidade, bem como respeitando suas opções e escolhas de cuidado em coparticipação enfermagem - cliente, tendo em vista o resgate ao protagonismo e direitos a cidadania.

O presente relato de experiência atende a Resolução do Conselho Nacional de Saúde 196/96, sendo Que foi aprovado pelo Comitê de ética e Pesquisa com Seres Humanos (Parecer $n^{\circ}$ 0033/2006). Utilizou-se o consentimento pós-informado, obtido após a experiência. $\mathrm{O}$ aceite dos participantes foi obtido por meio de Termo de Consentimento Livre e Esclarecido, sendo que receberam todas as informações sobre os resultados da experiência e sua estruturação e divulgação em forma de relato de experiência científica. A descrição desta experiência preservou o anonimato da instituição e dos participantes.

\section{DESCRIÇÃO DA EXPERIÊNCIA}

Durante o estágio os acadêmicos desenvolveram o cuidado de 
enfermagem, de acordo com as fases da Metodologia Científica da Assistência de Enfermagem: assessment, diagnóstico, planejamento, implementação e avaliação. Adotou-se o cuidado integral, como enfoque o tratamento de feridas. Além disso, foram realizadas sessões de educação em saúde, bem como atividades de lazer.

Os participantes (12) se distribuíram equitativamente entre masculino e feminino. A faixa etária variou entre 35 a 77 anos. Apenas seis eram alfabetizados. Quatro deles aposentados. Todos relataram falta de ocupação ou serviço, por falta de condições físicas para exercer QualQuer tipo de trabalho. Quase todos não possuíam família, nem tinham onde morar, sendo o motivo principal da permanência na instituição.

Apenas uma pessoa se encontrava em PQT, sendo Que os outros estavam curados, mas continuavam portadores de úlceras neutróficas crônicas e seQüelas associadas à hanseníase. Todos os participantes eram portadores de lesões cutâneas secundárias, crônicas de diferentes aspectos, sendo Que onze deles apresentavam seQüelas incapacitantes.

De acordo com os registros dos prontuários prevaleceu a hanseníase virchowiana (75\%), seguida pela dimorfa (17\%) e tuberculóide (8\%). Todos os participantes apresentavam lesões de aspecto grotesco e variado, Que apresentavam diferentes graus de extensão e profundidade, agravadas por contraturas e seQüelas. As características morfológicas das lesões e seqüelas segundo o tipo de hanseníase e sua freeüência estão descritas, respectivamente no Quadro - I e na Tabela 1.

\section{Procedimento de Cuidado e Autocuidado com as Lesões Cutanêas}

Todos os sujeitos tiveram suas úlceras e lesões examinadas, sendo Que o tipo de tratamento tópico foi investigado com enfoque nas

\begin{tabular}{|c|c|c|}
\hline $\mathrm{P}^{*}$ & Hanseníase* & Perfil morfologico de lesôes e seQüelas de hanseníase \\
\hline PI & $\begin{array}{l}\text { Virchowiana } \\
\text { Grau } 0\end{array}$ & $\begin{array}{l}\text { Lesões cutâneas difusas, eritemato-castanhadas, infiltradas, pele atrófica, anidrose e madarose. } \\
\text { Ulceraçôes nos pés. }\end{array}$ \\
\hline P2 & $\begin{array}{l}\text { Virchowiana } \\
\text { Grau } 2\end{array}$ & $\begin{array}{l}\text { Lesóes cutâneas difusas, eritemato-castanhadas, brilhantes, infiltradas, reabsorção discreta e } \\
\text { garra móvel das mãos, contratura dos pés e reabsorção discreta dos artelhos. Desabamento da } \\
\text { asa do nariz, déficit visual e madarose. Ulceração das pernas e dos pés. }\end{array}$ \\
\hline P3 & $\begin{array}{l}\text { Virchow } \\
\text { Grau } 2\end{array}$ & $\begin{array}{l}\text { Lesões cutâneas difusas, eritemato-castanhadas, brilhantes, infiltradas. Articulações } \\
\text { anquilosadas, contraturas das mãos e dos pés, discreta absorção das mãos. Desabamento da asa } \\
\text { do nariz, déficit visual, madarose, ulceração das pernas e dos pés. }\end{array}$ \\
\hline P4 & $\begin{array}{l}\text { Virchow } \\
\text { Grau } 2\end{array}$ & $\begin{array}{l}\text { Lesões tumorais (Quelóide) e sulfonoresistentes. Articulações anquilosadas, reabsorção intensa } \\
\text { e garra móvel das mãos, reabsorção discreta dos pés. Desabamento do nariz e madarose. } \\
\text { Ulceração das pernas e dos pés. }\end{array}$ \\
\hline P5 & $\begin{array}{l}\text { Virchowiana } \\
\text { Grau } 2\end{array}$ & $\begin{array}{l}\text { Lesóes difusas, eritemato-castanhadas, brilhantes, infiltradas. Reabsorsão acentuada dos pés } \\
\text { com perda de artelhos, pele atrófica, anidrose, desabamento da asa do nariz e madarose. } \\
\text { Ulceração das pernas e dos pés. }\end{array}$ \\
\hline P6 & $\begin{array}{l}\text { Vichorviana } \\
\text { Grau } 2\end{array}$ & $\begin{array}{l}\text { Lesões cutâneas difusas, eritemato-castanhadas, brilhantes, infiltradas. Lesões tumorais e } \\
\text { sulfonoresistentes. Articulações anQuilosadas, contraturas e reabsorção intensa das mãos. } \\
\text { Opacidade corneana, déficit visual acentuado e auditivo, desabamento do nariz e madarose. Mal } \\
\text { perfurante plantar. Ulceração das pernas e dos pés. }\end{array}$ \\
\hline P7 & $\begin{array}{l}\text { Virchowiana } \\
\text { Grau } 2\end{array}$ & $\begin{array}{l}\text { Lesões cutâneas difusas, eritemato-castanhadas, brilhantes, infiltradas. Lesóes tumorais e } \\
\text { sulfonoresistentes. Áreas de anestesia nas mãos e nos pés, articulaçôes das mãos e dos pés } \\
\text { anquilosadas. Reabsorção intensa de ambas as orelhas, desabamento do nariz, madarose e } \\
\text { déficit visual. Ulceração das pernas e dospés. }\end{array}$ \\
\hline P8 & $\begin{array}{l}\text { Virchowiana } \\
\text { Grau } 2\end{array}$ & $\begin{array}{l}\text { Lesôes cutâneas difusas, eritemato-castanhadas, brilhantes, infiltradas. Anestesia de braços e } \\
\text { mãos. Mãos caídas, com contraturas e garra móvel, ausência de ambas as pernas por } \\
\text { amputação. Desabamento do nariz e madarose. Ulceraçôes em todo corpo. }\end{array}$ \\
\hline P9 & $\begin{array}{l}\text { Virchowiana } \\
\text { Grau } 2\end{array}$ & $\begin{array}{l}\text { Lesóes cutâneas difusas e eritematosas. Presença de ulceraçóes diversas. Anestesia em partes dos } \\
\text { braços e pés, reabsorção acentuada com perda total e todos os dedos das mãos e alguns dedos } \\
\text { dos pés, mal perfurante plantar. Opacidade corneana, com déficit visual acentuado e madarose. }\end{array}$ \\
\hline P10 & $\begin{array}{l}\text { Dimorfa/pólo } \\
\text { Virchowiano } \\
\text { Grau } 2\end{array}$ & $\begin{array}{l}\text { Lesóes cutâneas pouco numerosas de contornos mal definidos, assimétricas acastanhadas e } \\
\text { infiltradas. Anestesia de mãos e de pés. Desabamento da asa do nariz, e madarose. Presença de } \\
\text { mal perfurante plantar. }\end{array}$ \\
\hline PII & $\begin{array}{l}\text { Dimorfa/pólo } \\
\text { tuberculóide } \\
\text { Grau I }\end{array}$ & $\begin{array}{l}\text { Lesóes cutâneas lisas, brilhantes, simétricas e hipocrômicas. Presença de áreas de anestesia nos } \\
\text { membros superiores e inferiores. Desabamento da asa do nariz e madarose. Ulceração das } \\
\text { pernas e dos pés.. }\end{array}$ \\
\hline$P I 2$ & $\begin{array}{l}\text { Tuberculbide } \\
\text { Grau } 2\end{array}$ & $\begin{array}{l}\text { Lesões cutâneas avermelhadas levemente elevadas em todo contorno. Anestesia em membros } \\
\text { superiores e inferiores, articulaçôes aneuilosadas, reabsorção discreta e contraturas das mãos e } \\
\text { pés e garra dos artelhos. Déficit visual, madarose, desabamento do nariz. Ulceração das pernas } \\
\text { e dos pés.. }\end{array}$ \\
\hline
\end{tabular}

Quadro I. Perfil de lesões cutâneas, seeüelas e grau de incapacidade de portadores de hanseníase. Anápolis, 2007. 
Tabela 1. Freqüência de lesões cutâneas e seQüelas de hanseníase em um grupo de pessoas asiladas em uma instituição de saúde não governamental do estado de Goiás. Anápolis, 2007.

\begin{tabular}{lc}
\hline \multicolumn{1}{c}{ Tipo de lesões cutâneas e seQüelas de hanseníase } & $\%$ \\
\hline Lesões cutâneas brilhantes difusas & 58,3 \\
Lesões cutâneas eritemato-castanhadas, infiltradas & 75,0 \\
Lesões cutâneas eritematosas difusas & 8,33 \\
Lesões cutâneas pouco numerosas de contornos mal definidos, & 8,33 \\
assimétricas & \\
Lesões cutâneas lisas, brilhantes, simétricas & 8,33 \\
Lesões cutâneas hipocrômicas & 8,33 \\
Lesões cutâneas levemente elevadas em todo contorno & 8,33 \\
Lesões tumorais & 33,3 \\
Lesões sulfono-resistentes & 33,3 \\
Anestesia em diferentes locais do corpo & 100 \\
Ulcerações diversas & 100 \\
Déficit visual & 50 \\
Opacidade corneana & 16,6 \\
Madarose & 100 \\
Desabamento da pirâmide nasal & 91,6 \\
Reabsorção da orelha & 8,33 \\
Articulações an@uilosadas & 100 \\
Reabsorção discreta das mãos & 25 \\
Reabsorção intensa das mãos & 25 \\
Garra móvel das mãos & 25 \\
Contratura das mãos & 33,3 \\
Contratura dos pés & 16,66 \\
Reabsorção de artelhos & 41,66 \\
Amputação de membros inferiores & 8,33 \\
\hline
\end{tabular}

soluções adotas para o curativo. Para melhor entendimento, as histórias clínicas foram categorizadas segundo a solução ou produto adotado no autocuidado das feridas: açúcar, povedine, permagananto de potássio, pomada antibiótica e dersani. O Quadro 2 consiste uma síntese da conduta adotada pelos participantes.

\section{DISCUSSÃO E REFLEXÕES SOBRE A VIVÊNCIA}

No Brasil, a trajetória da hanseníase aparece impregnada da visão medieval, até a década de setenta, Quando a sociedade se mobilizou para abolir o nome Lepra dos espaços sociais e de saúde. E mesmo após os resultados eficazes da polieuimioterapia, a vida do portador de hanseníase e suas seqüelas continua marcada pelo estigma, Que na maioria das vezes se inicia no seio familiar culminando na completa exclusão social ${ }^{(8)}$.

Observa-se Que as pessoas confinadas na instituição onde foi desenvolvida a experiência expressam a herança dos conceitos errôneos sobre a doença, a rejeição e o estigma social avassalador Que não permite a re-integração social, provocando a entrada no ciclo de doença - pobreza e a ruptura com a cidadania.

O fato de $91,6 \%$ dos participantes se eneuadrarem no grau de incapacidade II, demonstra Que não conseguiram realizar o tratamento profilático, permitindo ao bacilo franca instalação e acometimento dermato-neurológico, com desenvolvimento da doença em sua forma mais grotesca e mutilante.

Um estudo envolvendo 28 municípios de uma Regional de Saúde do estado do Paraná detectou Que $34,4 \%$ dos sujeitos apresentavam grau de incapacidade II, o Que expressa a magnitude dos prejuízos da doença à nação, Observa-se Que o grau de incapacidade mais comprometedor é freqüente mesmo nas pessoas não confinadas ${ }^{(10)}$.

Em relação à forma de hanseníase, prevaleceu a hanseníase virchowiana (HV), sendo Que 83,3\% apresentaram esta forma. Apenas duas pessoas apresentaram formas diferentes sendo uma tuberculóide e a outra dimorfa, mas com pólo de aproximação para HV. Este perfil explica o grave estado de saúde dos participantes caracterizado pela presença de úlceras extensas e disseminadas em 100\% deles, das Quais $41,6 \%$ apresentavam necrose, secreção e odor fétido.

De acordo com o Ministério da Saúde e outros estudos, as hanseníases virchowiana e dimorfa são as mais prevalentes na população, por serem as formas contagiantes da doença, sendo multibacilares, de carga bacilar significativa na derme e mucosas antes do início do tratamento ${ }^{(3,8)}$.

Todos os participantes apresentaram anestesia em diferentes áreas do corpo, madarose e articulações anфuilosadas, 92\% deles o desabamento da pirâmide nasal, 75\% lesões cutâneas eritematocastanhadas e infiltradas, 50\% déficit visual, 42\% reabsorção de 


\begin{tabular}{|c|c|c|c|}
\hline $\begin{array}{l}\text { Características } \\
\text { do participante }\end{array}$ & Local da úlcera e dimensão & $\begin{array}{l}\text { Tecido de granulação (TG) e aspecto das } \\
\text { bordas }\end{array}$ & Soluções utilizadas \\
\hline $\begin{array}{l}\text { PI- } 66 \text { anos - } \\
\text { Tipo VirchoWiana }\end{array}$ & $\begin{array}{l}\text { Região lateral pé D } \\
6 X 1 \mathrm{~cm} \\
\text { Região dorsal do pé D - } 5 \mathrm{X} \\
2 \mathrm{~cm}\end{array}$ & $\begin{array}{l}\text { TG presente em pequena Quantidade } \\
\text { úmido/róseo, sem necrose } \\
\text { Bordas bem definidas, pele adjacente } \\
\text { escurecida. }\end{array}$ & $\begin{array}{l}\text { Detergente } \\
\text { Açúcar }\end{array}$ \\
\hline $\begin{array}{l}\text { P2 - } 77 \text { anos } \\
\text { Tipo Virchowiana }\end{array}$ & $\begin{array}{l}\text { Perna D - } 12 \times 6 \mathrm{~cm} \\
\text { Perna e pé E - } 12 \times 15 \mathrm{~cm} \\
\text { Dorso do pé D }-5 \times 2 \mathrm{~cm}\end{array}$ & $\begin{array}{l}\text { TG em peQuena Quantidade } \\
\text { úmido/róseo. Discreta secreção amarelada e } \\
\text { tecido necrótico } \\
\text { Bordas irregulares, pele adjacente } \\
\text { escurecida. }\end{array}$ & $\begin{array}{l}\text { Detergente } \\
\text { Açúcar }\end{array}$ \\
\hline $\begin{array}{l}\text { P3 - } 53 \text { anos, } \\
\text { Tipo Virchowiana }\end{array}$ & $\begin{array}{l}\text { Perna e Pé D - } 22 \text { X } 18 \mathrm{~cm} \\
\text { Perna e pé E }-13 \times 11 \mathrm{~cm}\end{array}$ & $\begin{array}{l}\text { TG em peQuena Quantidade, } \\
\text { presença de grande Quantidade de tecido } \\
\text { necrótico. Bordas } \\
\text { irregulares, pele adjacente } \\
\text { escurecida. }\end{array}$ & $\begin{array}{l}\text { Detergente } \\
\text { Irrigação local com } \\
\text { Polivinilpirrolidona } \\
\text { (PVPI) }\end{array}$ \\
\hline $\begin{array}{l}\text { P4 - } 59 \text { anos } \\
\text { Tipo Virchowiana }\end{array}$ & $\begin{array}{l}\text { Perna e pé E } \\
15 \times 3 \mathrm{~cm}\end{array}$ & $\begin{array}{l}\text { TG úmido e róseo. Bordas bem definidas, } \\
\text { pele adjacente } \\
\text { rósea. }\end{array}$ & $\begin{array}{l}\text { Irregulares } \\
\text { Pele adjacente } \\
\text { Escurecida }\end{array}$ \\
\hline $\begin{array}{l}\text { P5 - } 35 \text { anos } \\
\text { Tipo Virchowiana }\end{array}$ & $\begin{array}{l}\text { Pernas e pés D e E } \\
\text { Cerca de } 1 \mathrm{~cm} \text { cada }\end{array}$ & $\begin{array}{l}\text { TG, úmido e róseo. Bordas irregulares, pele } \\
\text { adjacente escurecida. }\end{array}$ & $\begin{array}{l}\text { Detergente } \\
\text { Irrigação local com } \\
\text { PVPI e Vaselina }\end{array}$ \\
\hline $\begin{array}{l}\text { P6 - } 69 \text { anos } \\
\text { Tipo Virchowiana }\end{array}$ & $\begin{array}{l}\text { Dorso da mão D - IX2 cm } \\
\text { Pé direito - mal perfurante } \\
\text { plantar - } 2 X 2 \mathrm{~cm} .\end{array}$ & $\begin{array}{l}\text { TG, úmido e róseo. Bordas irregulares, pele } \\
\text { adjacente } \\
\text { escurecida. }\end{array}$ & $\begin{array}{l}\text { Detergente } \\
\text { Irrigação local com } \\
\text { PVPI }\end{array}$ \\
\hline $\begin{array}{l}\text { P7 - } 53 \text { anos } \\
\text { Tipo Virchowiana }\end{array}$ & $\begin{array}{l}\text { Perna }-1 \mathrm{Xl} \mathrm{cm} \\
\text { Dorso do pé D }-5 X 2 \mathrm{~cm} \\
\text { Pé E - } 4 \times 2 \mathrm{~cm} .\end{array}$ & $\begin{array}{l}\text { Apresentando grande Quantidade de tecido } \\
\text { necrótico. }\end{array}$ & $\begin{array}{l}\text { Compressas de } \\
\text { permanganato de } \\
\text { potássio e tratado } \\
\text { com pomada de } \\
\text { neomicina. } \\
\end{array}$ \\
\hline $\begin{array}{l}\text { P8 - } 43 \text { anos } \\
\text { Tipo Virchowiana }\end{array}$ & $\begin{array}{l}\text { Mão D - IXI cm } \\
\text { Antebraço e braço D } \\
11 X 3 \mathrm{~cm} \\
\text { Mão E - } 9 X 2 \mathrm{~cm} \text { Antebraço } \\
\mathrm{E}-4 X 4 \mathrm{~cm} \text { Braço E - } \\
10 X 2,5 \mathrm{~cm} \\
\text { Nádega D - } 8 X 3 \mathrm{~cm}, \\
\text { Nádega esQuerda }-15 X 3 \mathrm{~cm} \\
\text { Coxa E - } 20 X 7 \mathrm{~cm}\end{array}$ & $\begin{array}{l}\text { Todas as feridas apresentando grande } \\
\text { Quantidade de tecido necrótico. } \\
\text { PeQuena Quantidade de TG na coxa esquerda } \\
\text { e nádegas E de aspecto úmido e coloração } \\
\text { rósea. } \\
\text { Bordas irregulares, pele adjacente } \\
\text { coloração avermelhada, apresentando } \\
\text { cicatrização hipertrófica e nódulos. }\end{array}$ & $\begin{array}{l}\text { Compressas de } \\
\text { permanganato de } \\
\text { potássio e dersani. }\end{array}$ \\
\hline $\begin{array}{l}\text { P9 - } 63 \text { anos } \\
\text { Tipo Virchowiana }\end{array}$ & $\begin{array}{l}\text { Pé direito - mal perfurante } \\
\text { plantar } \\
4 \times 0,5 \mathrm{~cm}\end{array}$ & $\begin{array}{l}\text { TG ausente. Presença de necrose } \\
\text { Bordas irregulares. Pele adjacente necrosada. }\end{array}$ & $\begin{array}{l}\text { Detergente } \\
\text { Irrigação local com } \\
\text { PVPI }\end{array}$ \\
\hline $\begin{array}{l}\text { P10 - } 66 \text { anos } \\
\text { Tipo Dimorfa }\end{array}$ & $\begin{array}{l}\text { Pé direito - mal perfurante } \\
\text { plantar } \\
\mathrm{IXI} \mathrm{cm}\end{array}$ & $\begin{array}{l}\text { TG ausente. Presença de necrose. Bordas } \\
\text { bem definidas, pele adjacente pálida. }\end{array}$ & $\begin{array}{l}\text { Detergente } \\
\text { Irrigação local com } \\
\text { PVPI }\end{array}$ \\
\hline $\begin{array}{l}\text { PI 1 - } 53 \text { anos } \\
\text { Tipo Dimorfa }\end{array}$ & $\begin{array}{l}\text { Perna e pé direito } \\
\text { Cercas de } 5 \times 5 \mathrm{~cm} \text { cada }\end{array}$ & $\begin{array}{l}\text { TG em pequena Quantidade } \\
\text { úmido/róseo, sem necrose. Bordas } \\
\text { irregulares, pele adjacente escurecida. }\end{array}$ & $\begin{array}{l}\text { Detergente } \\
\text { Açúcar }\end{array}$ \\
\hline $\begin{array}{l}\text { P12 50anos } \\
\text { Tipo Tuberculóide }\end{array}$ & $\begin{array}{l}\text { Pé esQuerdo }-2 \times 5 \mathrm{~cm} \\
\text { Pé direito }-3 \times 2 \mathrm{~cm}\end{array}$ & $\begin{array}{l}\text { TG em pequena euantidade } \\
\text { úmido/róseo, sem necrose. Bordas } \\
\text { irregulares, pele adjacente pálida. }\end{array}$ & $\begin{array}{l}\text { Detergente } \\
\text { Irrigação local com } \\
\text { PVPI }\end{array}$ \\
\hline
\end{tabular}

* Soluçôes de limpeza e tópicas.

Quadro 2. História de portadores de lesões secundárias associadas à hanseníase e autocuidado tópico das lesões cutâneas. Ano 2007.

artelhos, 34\% lesões tumorais e sulfono-resitentes, 33\% contraturas das mãos e pés, 25\% reabsorção e garra móvel da mão, 25\% mal perfurante plantar.

A presença de lesões cutâneas e seQüelas mutilantes, da natureza das encontradas neste estudo, denota a gravidade do estado de saúde, do risco de infecção e da baixa Qualidade de vida dessas pessoas. Nesse sentido, o estudo de Martins et al ${ }^{(11)}$ comprova a associação entre as formas multibacilares de hanseníase e a baixa 
Qualidade vida. Além disso, detectaram Que $85 \%$ dos pacientes com grau de incapacidade física I e II apresentam episódio reacional no decorrer da evolução clínica da doença.

Em relação ao uso de sabão líquido (detergente doméstico) utilizado para limpeza das úlceras, por 100\% dos participantes, consideramos um fato novo e de certa forma intrigante, pois por mais científicas que fossem nossas argumentações, percebemos Que não foram convincentes.

Nesse sentido, acreditamos Que a falta de sensibilidade no leito da ferida, agravada pela falta de conhecimento sobre a importância de se preservar o tecido de granulação, propicia o uso do sabão, certamente pelo fato do odor desagradável causar mais desconforto, além de baixa auto - estima e comportamento de isolamento, em detrimento a própria cicatrização, vista com total desesperança.

Fato confirmado, pelos participantes na escolha de soluções de efeito adstringente, Que diminuem a secreção e o odor, tais como: PVPI (50\%), açúcar (25\%), permanganato de potássio $(16,6 \%)$ e Dersani $(8,33 \%)$.

Neste contexto, acadêmicos e professores fizeram algumas inferências em relação ao grau de agressão e possíveis resultados nas lesões ${ }^{(7,12)}$ :

- Dersani, nos pareceu o mais adequado, por ser a base de ácido linoléico, percussor de substâncias farmacologicamente ativas envolvidas no processo de divisão celular e diferenciação epidérmica, Que promove a Quimiotaxia dos leucócitos, a neoangiogênese, o meio úmido, acelerando o processo de granulação. É facilmente disponível, de baixo custo e pode ser associado a diversos tipos de coberturas.

- PVPI, é ineficaz na presença de substância orgânica, além de ser tóxico aos polimorfonucleares e fibroblastos, inibindo o tecido de granulação e retardando a cicatrização;

- permanganato de potássio, é tão citotóxico as células da cicatrização, Quanto os outros anti-sépticos, por isso dificulta a granulação;

- açúcar provoca um meio hiperosmótico, apresentando um efeito bactericida, no entanto após duas horas de contato com o leito da ferida, torna-se um meio de cultura, perdendo o poder de alterar a osmolaridade das bactérias e o efeito bactericida, alguns autores referem sua ação no controle do odor e seu baixo custo como atrativos à sua escolha pelas pessoas em diferentes situações;

- pomadas com antibiótico são contra indicadas, pois além do efeito praticamente nulo, devido a baixa concentração nas camadas tissulares, induzem a resistência bacteriana, hipersensibilidade e atrapalham o processo cicatricial.

Dessa forma, consideramos Que o problema instalado está no âmbito das Questões de habitus e crenças de autocuidado em saúde, as Quais entendemos Que devem ser abarcadas como eixo estruturante das competências profissionais de saúde, no âmbito da atenção básica. Dessa forma, consideramos Que a melhor estratégia de resolução seja a educação continuada e a capacitação dos voluntários da referida instituição, dentre eles estudantes de enfermagem de diferentes categorias.

Verificamos ainda a necessidade da elaboração de protocolos de cuidar de feridas e instituição de normas e rotinas para a assistência holística dos clientes.

O conhecimento por nós construído, durante essa pesquisa, nos permitiu apreender mais sobre a hanseníase, e com certeza poderá contribuir com o conhecimento científico de pessoas envolvidas nessa especialidade.

$\mathrm{Na}$ investigação do tipo de conduta adotada para o tratamento tópico das feridas, consideramos um fator agravante do Quadro clínico, o comportamento inadeQuado na escolha e uso de soluções, expresso pelo uso de substâncias citotóxicas e totalmente adversas às diretrizes da Agência Nacional de Vigilância Sanitária de outros referenciais teóricos da área.

\section{REFERÊNCIAS}

1. Ministério da Saúde (BR). Secretaria de Vigilância em Saúde. Doenças infecciosas e parasitárias : guia de bolso. $5^{\mathrm{a}}$ ed. Brasília: Ministério da Saúde; 2005.

2. Rede Interagencial de Informação para a Saúde. Indicadores básicos para a saúde no Brasil: conceitos e aplicações. Brasília: Organização Pan-Americana da Saúde; 2008.

3. Ministério da Saúde (BR). Secretaria de Vigilância da Saúde. Nota técnica n ${ }^{\circ} 0$ de 2007 do Programa Nacional de Controle da Hanseníase. Indicador de monitoramento do comportamento de hanseníase no Brasil. Brasília: Ministério da Saúde; 2007.

4. Ministério da Saúde (BR). Secretaria de Políticas Públicas de Saúde. Departamento de atenção básica. Guia de controle da hanseníase. Brasília: Ministério da Saúde; 2002.

5. Polit DF, Beck CT, Hungler BP. Fundamentos da pesquisa em enfermagem: métodos, avaliação e utilização. Porto Alegre: Artmed; 2004.

6. Christensen IP. Assessment overwiew of data collection. In: Christensen IP, Kenney IW. Nursing process - application of theories, frameworks, and models. $2^{\text {nd }}$ ed. St. Louis: Mosby; 1986. p. 61-9.
7. Ministério da Saúde (BR). Secretaria de Políticas Públicas de Saúde. Departamento de atenção básica. Área técnica de dermatologia sanitária. Manual de condutas para úlceras neutróficas. Brasília: Ministério da Saúde; 2002.

8. Sobrinho RAS, Mathias TAF, Gomes EA, Lincoln PB. Avaliação do grau de incapacidade me Hanseníase. Rev Latino-Am Enfermagem 2007; 15(6): 1125-30.

9. Monteiro Y N. Violência e profilaxia: os preservatórios paulistas para filhos de portadores de hanseníase. Saúde Sociedade 1998; 7(1): 3-26.

10. Helene LMF, Salum M JL.. A reprodução social da hanseníase: um estudo do perfil de doentes com hanseníase no Município de São Paulo. Cad Saúde Pública 2002; 18(1): 101-13.

I I. Martins BDL, Torres FN, Oliveira M L WDR. Impacto na eualidade de vida em pacientes com hanseníase: correlação do Dermatology Life Quality Index com diversas variáveis relacionadas à doença. Anais Bras Dermatol 2008; 83(I): 39-43.

12. Tuyama LY. Feridas crônicas de membros inferiores: proposta de sistematização da assistência de enfermagem ambulatorial. Rev Nursing 2004; 75 (2): 46-50. 